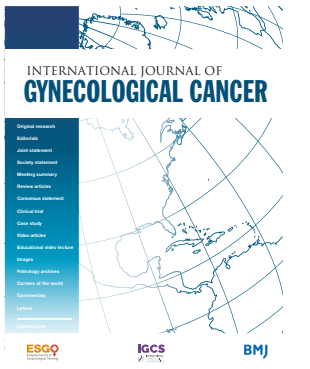

${ }^{1}$ Clinica Universidad de Navarra Departamento de Ginecologia y Obstetricia, Madrid, Spain ${ }^{2}$ Department of Thoracic Surgery, Clinica Universidad de Navarra, Madrid, Spain ${ }^{3}$ Department of Gynecology, Clinica Universitaria de Navarra, Madrid, Spain

${ }^{4}$ Department of Obstetrics and Gynecology, Universidad de Navarra, Pamplona, Navarra, Spain

${ }^{5}$ Department of Obstetrics and Gynecology, Clinica Universidad de Navarra, MADRID, Spain

Correspondence to Dr Felix Boria, Clinica Universidad de Navarra Departamento de Ginecologia y Obstetricia, Madrid 28027, Spain; f.boria.alegre@gmail. com

Accepted 15 October 2020 Published Online First 4 November 2020

\title{
PleurX indwelling pleural catheter for the treatment of recurrent pleural effusion in advanced ovarian cancer
}

Felix Boria (D) , ${ }^{1}$ Maria Rodriguez-Perez, ${ }^{2}$ Daniel Vázquez-Vicente (D) , ${ }^{3}$ Teresa Castellanos, ${ }^{3}$ Enrique Chacon, ${ }^{4}$ Luis Chiva (i) ${ }^{5}$

One of the most distressing manifestations of advanced ovarian malignancy is the development of a symptomatic pleural effusion. Left untreated, malignant pleural effusions can cause significant morbidity, affecting prognosis and quality of life. Effective drainage of this fluid and prevention of its recurrence is crucial if we want to improve both the quality of life and the life expectancy of these patients. ${ }^{1}$

Several treatment options are available for a malignant pleural effusion, such as intermittent outpatient thoracentesis, pleuroperitoneal shunt, or a pleurodesis using a sclerosing agent. ${ }^{2}$

A PleurX catheter is a fenestrated $15.5 \mathrm{Fr}$ elastomer catheter that was designed for the outpatient management of malignant pleural effusions. A polyester cuff at its end allows tissue ingrowth and protection from infection. Once the catheter is placed, the patient can easily drain pleural effusions at home as many times as needed. ${ }^{1}$

Patients who will benefit most from this technique are those with malignant pleural effusions requiring multiple pleural drainages, failed previous pleurodesis procedures, challenging lung anatomy that complicates a successful pleurodesis, and those with a shortened life expectancy. ${ }^{3}$

The main risk of this procedure is catheter infection, which can generate a subcutaneous abscess. Caution must be taken in order to guarantee a proper aseptic technique during all the procedure.

Although a PleurX catheter can be easily inserted without thoracoscopy, we present a useful technique to implement at time of diagnostic thoracoscopy, performed in the context of an advanced ovarian malignancy. ${ }^{4}$

Direct visualization assures an appropriate pleural space placement, without adding much more time or morbidity to the diagnostic thoracoscopy procedure.

After the diagnostic thoracoscopy, we make a 1 to 2 $\mathrm{cm}$ incision at $5 \mathrm{~cm}$ from the thoracoscopy trocar site. We then pass the tunneler and the catheter subcutaneously through the trocar incision until the polyester cuff is inside the skin. Finally, we introduce the catheter into the pleural cavity under direct visualization. Once inserted, we close the trocar incision and fix the catheter to the skin. The insertion of the PleurX catheter outpatient drainage system is explained step-by-step in video 1.

\section{PleurX indwelling pleural catheter for the treatment of recurrant pleural effusion}

Check for updates

(C) IGCS and ESG0 2021. No commercial re-use. See rights and permissions. Published by BMJ.

\begin{tabular}{l}
\hline To cite: Boria F, \\
Rodriguez-Perez M, \\
Vázquez-Vicente D, et al. Int J \\
Gynecol Cancer 2021;31:635- \\
636. \\
\hline
\end{tabular}

Boria F; Rodriguez M; Castellanos T; Vázquez-Vicente D; Chiva L

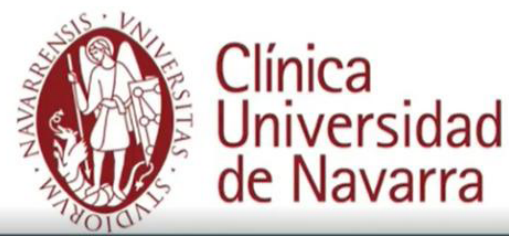

Video 1 PleurX indwelling catheter for malignant pleural effusions treatment. 


\section{Video article}

\section{Twitter Felix Boria @BoriaFelix}

Contributors All authors made substantial contributions to the conception of the work. FB: video edition, video locution, abstract. MR: video edition, abstract. TC, DV-V, LC: design and review of the video and abstract. All authors agree to be accountable for all aspects of the work in ensuring that questions related to the accuracy or integrity of any part of the work are appropriately investigated and resolved.

Funding The authors have not declared a specific grant for this research from any funding agency in the public, commercial or not-for-profit sectors.

Competing interests None declared.

Patient consent for publication Not required.

Provenance and peer review Not commissioned; externally peer reviewed.

Data availability statement All data relevant to the study are included in the article.

\section{ORCID iDs}

Felix Boria http://orcid.org/0000-0002-4761-6190

Daniel Vázquez-Vicente http://orcid.org/0000-0002-9618-5606

Luis Chiva http://orcid.org/0000-0002-1908-3251

\section{REFERENCES}

1 Warren WH, Kalimi R, Khodadadian LM, et al. Management of malignant pleural effusions using the Pleur $(\mathrm{x})$ catheter. Ann Thorac Surg 2008;85:1049-55.

2 Davies HE, Lee YCG. Management of malignant pleural effusions: questions that need answers. Curr Opin Pulm Med 2013;19:374-9.

3 Chalhoub M, Saqib A, Castellano M. Indwelling pleural catheters: complications and management strategies. $J$ Thorac Dis 2018;10:4659-66.

4 Cohen-Mouly S, Badia A, Bats A-S, et al. Role of video-assisted thoracoscopy in patients with ovarian cancer and pleural effusion. Int J Gynecol Cancer 2009;19:1662-5. 